\title{
Release of LHRH in vitro and anterior pituitary responsiveness to LHRH in vivo during sexual maturation in pullets (Gallus domesticus)
}

\author{
P. G. Knight, R. T. Gladwell and F. J. Cunningham
}

Department of Physiology \& Biochemistry, The University, Whiteknights, Reading RG6 2AJ, U.K.

\begin{abstract}
Summary. An in-vitro superfusion technique was used to study basal and depolarization-induced $\left(32 \mathrm{mmol} \mathrm{K} \mathrm{K}^{+} / \mathrm{l}\right)$ release of $\mathrm{LHRH}$ from the mediobasal hypothalamus $(\mathrm{MBH})$ of pullets at 8-25 weeks of age. Plasma LH concentrations and the incremental change $(\Delta \mathrm{LH})$ after an i.v. injection of 1 or $15 \mu \mathrm{g}$ synthetic ovine $\mathrm{LHRH} / \mathrm{kg}$ body weight were also determined. Between 8 and 25 weeks of age, significant $(P<0.01)$ increases in basal and depolarization-induced release of LHRH (93 and 330\%, respectively) were accompanied by a significant $(P<0.01)$ rise in the residual LHRH content of MBH tissue $(152 \%$ ), observations which suggest that the ability of the hypothalamus to synthesize and secrete LHRH increases as sexual maturation proceeds. However, plasma $\mathrm{LH}$, which reached a maximum concentration of $2.05 \pm$ $0.43 \mu \mathrm{g} / \mathrm{l}$ at 15 weeks, fell significantly $(P<0.05)$ to $1.14 \pm 0.05 \mu \mathrm{g} / \mathrm{l}$ at 25 weeks. Since $\triangle \mathrm{LH}$ in response to exogenous LHRH showed a marked and progressive decline between 12 and 20 weeks of age, the low plasma concentration of LH typical of the mature hen is probably attributable to a direct negative-feedback action of ovarian steroids on the anterior pituitary gland rather than to an impaired secretion of LHRH from the median eminence. It is suggested that a dramatic increase in the responsiveness of LHRH nerve terminals in the $\mathrm{MBH}$ to depolarization by $32 \mathrm{mmol}$ $\mathrm{K}^{+} / 1$ between 20 and 25 weeks of age (mean age at onset of lay 21.9 weeks; range 19-25 weeks) may reflect the development of hypothalamic responsiveness to the positive feedback action of progesterone.
\end{abstract}

\section{Introduction}

In birds, as in mammals, sexual maturation involves profound readjustments to the activity of the hypothalamic-pituitary-ovarian axis (see reviews by Sharp \& Fraser, 1978; Sharp, 1983). In the domestic fowl, a prepubertal rise in the concentrations of luteinizing hormone (LH) (Wilson \& Sharp, 1975; Sharp, 1975; Williams \& Sharp, 1977) and of oestrogen (Senior, 1974; Peterson \& Webster, 1974) at about 15 weeks of age precedes the onset of lay by some 4-8 weeks. Thereafter plasma LH concentrations fall (Wilson \& Sharp, 1975; Sharp, 1975; Williams \& Sharp, 1977), presumably due to an enhanced negative-feedback action of raised ovarian steroids, probably oestradiol, on the hypothalamic-pituitary complex (Sharp, 1980). Despite this, it is only when plasma oestradiol concentrations decline during the final stages of development of the first preovulatory follicle (Senior, 1974) that the hypothalamic-pituitary complex acquires the ability to release $\mathrm{LH}$ in response to a positive feedback action of progesterone secreted by the preovulatory follicle (Wilson \& Sharp, 1975; Sharp, 1980; R. T. Gladwell, unpublished observations). Whilst hypothalamic neurones that release LHRH undoubtedly play a crucial role in these events, methodological limitations have hitherto precluded attempts to probe their involvement. The development of a heterologous radioimmunoassay for avian LHRH (Knight, Cunningham \& Gladwell, 1983) capable of detecting picogram amounts of LHRH released from isolated chicken mediobasal hypothalamus in vitro (Knight, 1983), prompted the present investigation of 
maturational changes in (1) basal and depolarization-induced release of LHRH from mediobasal hypothalamus tissue in vitro, (2) residual tissue content of LHRH in the mediobasal hypothalamus, (3) anterior pituitary responsiveness to exogenous LHRH in vivo and (4) plasma concentrations of $\mathrm{LH}$ in pullets of 8-25 weeks of age.

\section{Materials and Methods}

LHRH release in vitro. Ross-Brown pullets (Ross Poultry, Andover, Hants) were reared under a lighting schedule of $8 \mathrm{~h}$ light : $16 \mathrm{~h}$ darkness (lights on $08: 00 \mathrm{~h}$ ) with free access to food and water. Between $11: 30$ and $12: 00 \mathrm{~h}$ groups of 10 birds were killed by decapitation at $8,12,15,18,20$ and 25 weeks of age. The mean age at onset of lay of the 10 birds killed at 25 weeks of age was 21.9 weeks (range 19-25 weeks). The brains were rapidly removed and the mediobasal hypothalamus was excised using fine scissors and placed in a bicarbonate-buffered artificial avian cerebrospinal fluid (ACSF) which was gassed with $95 \% \mathrm{O}_{2}: 5 \% \mathrm{CO}_{2}$ to maintain a $\mathrm{pH}$ of $7 \cdot 3$ (Knight, 1983). The mediobasal hypothalamus, which included the entire median eminence, consisted of a $2 \mathrm{~mm}$ cube of tissue with a rostral limit coinciding with the caudal margin of the optic chiasma and the lateral limits about $1 \mathrm{~mm}$ either side of the third ventricle. The method used for the superfusion of such isolated tissue fragments has been fully described elsewhere (Knight, 1983). Briefly, tissue from 2 pullets was transferred at random to each of 5 superfusion chambers and ACSF medium was passed through each chamber at a flow rate of $25 \mu 1 / \mathrm{min}$. The superfusion chambers were immersed in a water bath maintained at $39^{\circ} \mathrm{C}$ and after a $1 \mathrm{~h}$ equilibration period three 20 -min fractions of superfusate were collected in chilled plastic tubes. A depolarizing stimulus which consisted of a 20 min pulse of ACSF medium containing a 5 -fold excess of potassium ions $(32 \mathrm{mmol} / \mathrm{l})$ was then passed through each chamber and a further three 20 -min fractions of superfusate were collected. At the end of the superfusion period the mediobasal hypothalamic tissue was recovered from each chamber and extracted for subsequent determination of the residual content of LHRH. Superfusate fractions and tissue extracts were stored at $-70^{\circ} \mathrm{C}$ until assayed for LHRH using the radioimmunoassay method described previously (Knight et al., 1983; Knight, 1983). Concentrations of LHRH are expressed in terms of a synthetic preparation of chicken LHRH (kindly provided by Professor R. P. Millar, Cape Town, S. Africa) rather than the synthetic ovine LHRH used in previous studies. A series of potency comparisons $(n=6)$ revealed that the chicken LHRH standard was 1.52 times more potent than the ovine LHRH standard in inhibiting the binding of ${ }^{125}$ I-labelled ovine LHRH to the antibody. Duplicate portions $(200 \mu \mathrm{l})$ of superfusate fractions were assayed without further dilution while tissue extracts were diluted 50-300 times before assay. Within- and between-assay coefficients of variation were 8 and $11 \%$ respectively and the limit of detection of the assay was approximately $1 \mathrm{pg} / \mathrm{tube}$.

Pituitary responsiveness to exogenous $L H R H$. Between $11: 00$ and $12: 00 \mathrm{~h}$ blood $(1 \mathrm{ml})$ was withdrawn from a wing vein of 10 pullets at $8,12,15,18,20$ and 25 weeks of age. Five pullets were subsequently given an intravenous injection of $1 \mu \mathrm{g}$ synthetic ovine LHRH (Sigma Chemicals Ltd, Poole, Dorset) $/ \mathrm{kg}$ body weight dissolved in $0.5 \mathrm{ml} 0.75 \%(\mathrm{w} / \mathrm{v}) \mathrm{NaCl}$ while the other 5 received an injection of $15 \mu \mathrm{g} \mathrm{LHRH} / \mathrm{kg}$. Further blood samples were withdrawn from the contralateral wing vein 5 and $15 \mathrm{~min}$ later. Blood was centrifuged for $10 \mathrm{~min}$ at $2000 \mathrm{~g}$ and the plasma was separated and stored at $-20^{\circ} \mathrm{C}$ until assayed for $\mathrm{LH}$ using the homologous radioimmunoassay described by Follett, Scanes \& Cunningham (1972). Within- and between-assay coefficients of variation were 6 and $10 \%$ respectively and the limit of detection of the assay was $40 \mathrm{pg} /$ tube.

Statistical analyses. To facilitate statistical analysis of the LHRH release data the total amount of LHRH released by each pair of mediobasal hypothalamic fragments during the first (basal LHRH release) and second hour of fraction collection (depolarization-induced LHRH release) was calculated. The effects of age on basal and depolarization-induced LHRH release, residual LHRH 
content, concentration of $\mathrm{LH}$ in plasma and incremental change in plasma LH concentration after the administration of LHRH $(\Delta \mathrm{LH})$ were analysed by one-way analysis of variance. Comparisons were subsequently made using Duncan's New Multiple Range test (Duncan, 1955).

\section{Results}

Text-figure 1 shows the patterns of LHRH release from superfused fragments of mediobasal hypothalamus obtained from the least ( 8 weeks old) and most ( 25 weeks old) mature pullets studied. The basal rate of LHRH release (fractions $1-3$ ) was approximately 2 -fold greater in 25 -week-old than in 8-week-old pullets. Exposure of mediobasal hypothalamic tissue to a 20-min pulse of ACSF medium containing a 5-fold excess of potassium ions caused only a slight increase in LHRH release in 8-week-old pullets but a dramatic response in 25-week-old pullets. The effects of age on basal and depolarization-induced release of LHRH are shown more fully in Text-fig. 2(a). Between 8 and 18 weeks of age neither basal nor depolarization-induced release of LHRH increased significantly. However, the mean value for depolarization-induced release of LHRH from the mediobasal hypothalamus (MBH) increased progressively from $40.2 \pm 6.4 \mathrm{pg} / 2 \mathrm{MBH} / \mathrm{h}$ at 8 weeks to $61.0 \pm$ $10.9 \mathrm{pg} / 2 \mathrm{MBH} / \mathrm{h}$ at 18 weeks. By 20 weeks depolarization-induced LHRH had reached $75.9 \pm 8.8$ $\mathrm{pg} / 2 \mathrm{MBH} / \mathrm{h}$, a value significantly $(P<0.05)$ greater than that at 8 or 12 weeks. A further dramatic $2 \cdot 5$-fold increase occurred between 20 and 25 weeks coincident with the onset of lay $(190.2 \pm 22.2$ $\mathrm{pg} / 2 \mathrm{MBH} / \mathrm{h}$ at 25 weeks $;<<0.01$ compared with all other ages studied). Although basal release of LHRH showed less pronounced changes associated with age, the rates of release at 20 and 25 weeks were significantly $(P<0.05)$ higher than at 8,15 or 18 weeks. The residual tissue content of LHRH (Text-fig. 2b) increased significantly $(P<0.01)$ from $13.7 \pm 2.7 \mathrm{ng} / 2 \mathrm{MBH}$ at 8 weeks to a

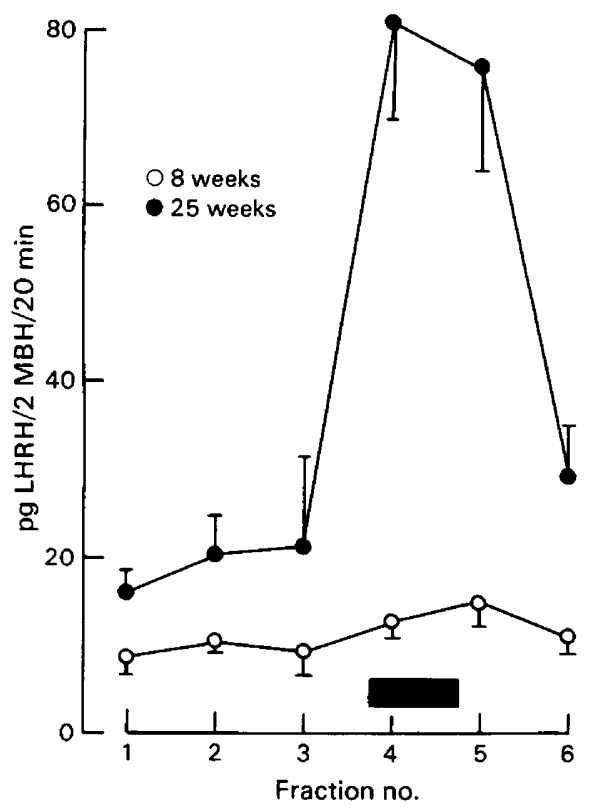

Text-fig. 1. Basal and depolarization-induced release of LHRH from the superfused mediobasal hypothalamus (MBH) of pullets killed at 8 or 25 weeks of age. After collecting three 20 -min fractions of superfusate a depolarizing stimulus consisting of a 20 -min pulse of medium containing a 5 -fold excess of potassium ions $(32 \mathrm{mmol} / \mathrm{l})$ was passed through each superfusion chamber (horizontal bar). Values are means $(n=5)$ and vertical lines indicate s.e.m. 


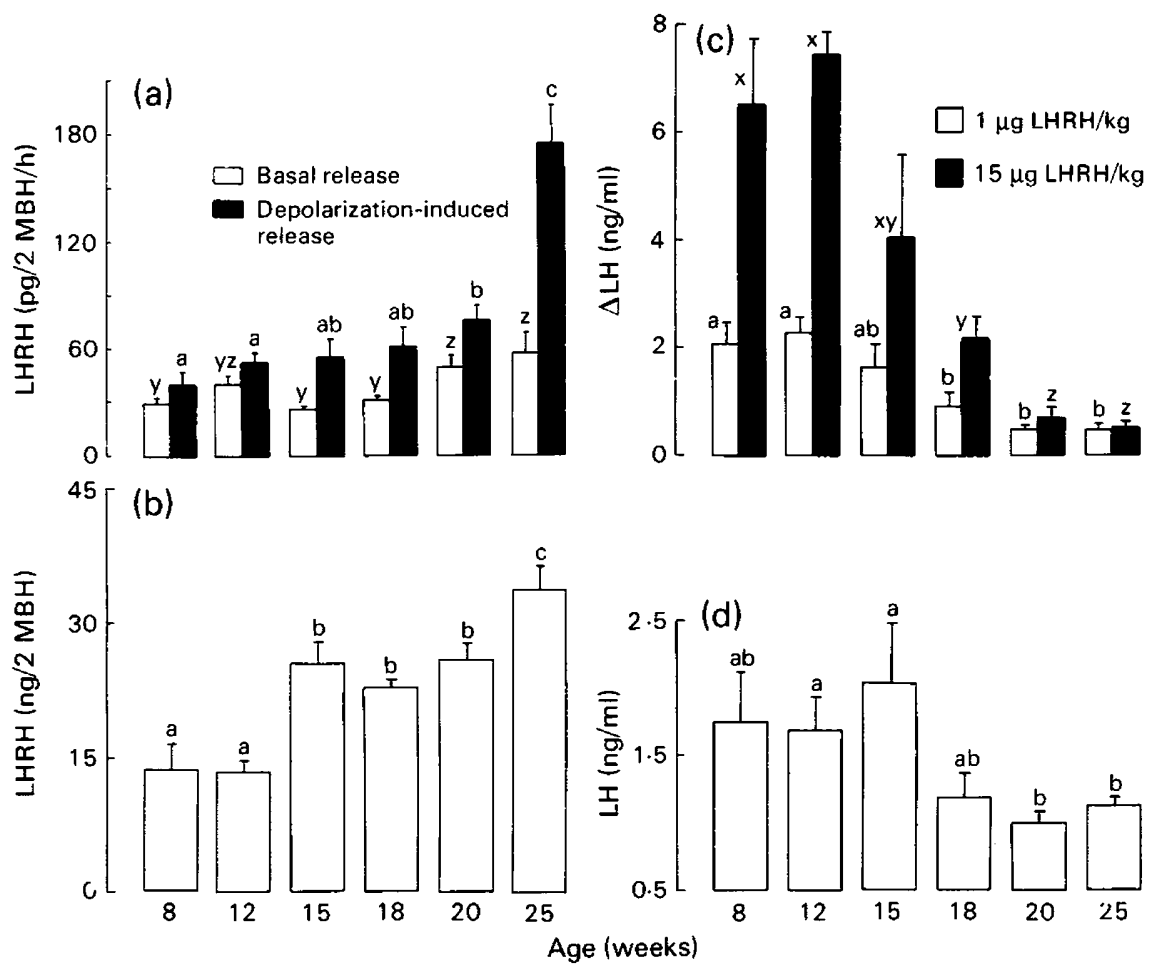

Text-fig. 2. Changes in (a) basal and depolarization ( $32 \mathrm{mmol} \mathrm{K}+1)$-induced release of LHRH from the superfused mediobasal hypothalamus (MBH), (b) residual content of LHRH in the MBH after superfusion, (c) maximum incremental change in plasma concentration of LH $(\Delta \mathrm{LH})$ after an intravenous injection of 1 or $15 \mu \mathrm{g}$ synthetic ovine $\mathrm{LHRH} / \mathrm{kg}$ body weight $(n=$ $5)$ and (d) concentrations of $\mathrm{LH}$ in plasma $(n=10)$ in pullets throughout sexual maturation. Values are means \pm s.e.m. Multiple 'between-age' comparisons were made and means without a common letter are significantly different $(P<0.05)$.

maximum value of $34.7 \pm 2.6 \mathrm{ng} / 2 \mathrm{MBH}$ at 25 weeks, with a particularly abrupt rise $(P<0.01)$ occurring between 12 and 15 weeks. The effect of age on the responsiveness of the anterior pituitary gland to exogenous LHRH, expressed in terms of the maximum increment in plasma LH concentration 5 or $15 \mathrm{~min}$ after its administration $(\Delta \mathrm{LH})$, is shown in Text-fig. 2(c). In contrast with basal and depolarization-induced LHRH release in vitro, $\Delta \mathrm{LH}$ in response to 1 or $15 \mu \mathrm{g}$ $\mathrm{LHRH} / \mathrm{kg}$ body weight was maximal at 8 and 12 weeks of age, showing a marked and progressive decline $(P<0.01)$ to a minimum value at 25 weeks. Similarly, basal concentrations of LH in plasma were significantly $(P<0.05)$ higher in younger $(8-15$ weeks) than in older $(20-25$ weeks) birds although a significant prepubertal rise in plasma LH concentration was not detected (Textfig. 2d).

\section{Discussion}

The use of an in-vitro superfusion technique coupled with a sensitive radioimmunoassay for avian LHRH has enabled us to examine certain properties of the hypothalamic LHRH neuronal system in pullets throughout sexual maturation. Isolated mediobasal hypothalamic tissue from mammals has been used successfully to study neuropeptide and neurotransmitter release in vitro (Rotsztejn, Charli, Pattou, Epelbaum \& Kordon, 1976; Gallardo \& Ramirez, 1977; Becker \& Ramirez, 1980; 
Drouva, Epelbaum \& Kordon, 1982) and, as demonstrated previously (Knight, 1983), the chicken mediobasal hypothalamus is equally amenable to such in-vitro studies.

The present results indicate that sexual maturation in pullets is accompanied by an increase in the LHRH content of the mediobasal hypothalamus and a concomitant rise in the basal rate of LHRH release from nerve terminals within the tissue. These observations are consistent with earlier findings for the cockerel (Knight, 1983) of increases in LHRH content and release during sexual development, although the magnitude of the increase in LHRH content of the mediobasal hypothalamus was substantially less in pullets than in cockerels. When mediobasal hypothalamic tissue was exposed to a standard sub-maximal depolarizing stimulus, in the form of a 20 -min pulse of ACSF medium containing a concentration $(32 \mathrm{mmol} / \mathrm{l})$ of potassium ions above the threshold concentration required to stimulate LHRH release but below that required for maximal release (P. G. Knight, unpublished observations), a number of features emerged. Whereas in 8- and $12-$ week-old pullets this stimulus evoked only a marginal and non-significant release of LHRH, from 15 to 25 weeks of age significant responses were observed. Moreover, between 20 and 25 weeks of age, coincident with the onset of lay in these birds, a striking increase in the magnitude of the response to depolarization occurred. It is possible that these alterations in the responsiveness of LHRH nerve terminals in the mediobasal hypothalamus to a depolarizing stimulus are related to developmental changes in the functional organization of the hypothalamus-pituitary complex with respect to the feedback actions of ovarian steroids. Thus, at 8 and 12 weeks of age, when both the responsiveness of LHRH nerve terminals and the LHRH content of mediobasal hypothalamus are lowest, relatively high levels of LH in plasma are maintained due to the fact that the responsiveness of the anterior pituitary gland to LHRH is maximal at this time. The low concentrations of both oestradiol (Senior, 1974; Peterson \& Webster, 1974) and progesterone (Williams \& Sharp, 1977) in the circulation at these times presumably account for the high responsiveness of the anterior pituitary gland to LHRH (Sharp, 1983). Between 12 and 20 weeks of age, a marked and progressive decline in anterior pituitary responsiveness to LHRH occurred, an observation consistent with previous studies in fowl (Bonney, Cunningham \& Furr, 1974; Wilson \& Sharp, 1975). Since the onset of ovarian development at about 15 weeks of age is associated with a gradual rise in plasma concentrations of oestradiol which reach a peak a few weeks before the onset of lay (Senior, 1974; Peterson \& Webster, 1974), this loss of anterior pituitary responsiveness to LHRH may be due to a direct negative-feedback action of the steroid (Sharp, 1980). Indeed, the observation that plasma LH concentrations declined between 15 and 20 weeks of age, despite the fact that basal and depolarization-induced LHRH release and LHRH content of the mediobasal hypothalamus did not, suggests that the fall in LH is entirely due to the action of oestrogen on the anterior pituitary gland. The question then arises: do ovarian oestrogens also exert a negative-feedback action at the hypothalamic level? It could be argued from the present data that whilst oestrogen feedback might limit the ability of the hypothalamus to synthesize and secrete LHRH, it certainly does not bring about a decline in LHRH neuronal activity and might even enhance it. However, since ovariectomy of pullets at 12 weeks of age causes a rise in plasma concentrations of LH (Sharp, 1973), the latter possibility seems unlikely. There is substantial evidence implicating central catecholaminergic neurones in the regulation of $\mathrm{LHRH}$ release, and the rise in plasma $\mathrm{LH}$ secretion in the pullet after ovariectomy is accompanied by an increased catecholamine content of several discrete hypothalamic regions, including the paraventricular nucleus and mediobasal hypothalamus (Knight, Gladwell \& Cunningham, 1981). It would be unwise, therefore, to disregard the possibility that at least part of the negative-feedback action of oestrogen on LH secretion is mediated at the central neural level.

During the last few weeks before the onset of lay the plasma concentration of oestradiol declines (Senior, 1974; Peterson \& Webster, 1974) and that of progesterone rises as the largest ovarian follicles enter their final rapid phase of growth (Furr, 1969; Williams \& Sharp, 1977). This period coincides with the maturation of the positive-feedback mechanism whereby progesterone secreted by the ovary acts on the hypothalamic-pituitary complex to stimulate the release of LH (Wilson \& 
Sharp, 1975). The present observation that the onset of lay was accompanied by a dramatic increase in the stimulus-evoked release of LHRH from mediobasal hypothalamic nerve terminals, as well as a significant rise in the LHRH content of the mediobasal hypothalamus, indicates that in the sexually mature hen increased plasma concentrations of progesterone, possibly in combination with lower oestrogen levels, could decrease the threshold for excitation of LHRH neurones and thereby facilitate LHRH release. In support of this view, other studies, using rat mediobasal hypothalamus in vitro, have shown that previous exposure of oestradiol-primed ovariectomized rats to progesterone (Ramirez, Dluzen \& Lin, 1980) or exposure of mediobasal hypothalamic tissue in vitro to progesterone (Rasmussen \& Yen, 1983) stimulate LHRH release. Since the preovulatory surge of LH in the laying hen is accompanied by a $50 \%$ depletion of hypothalamic LHRH content (Knight, Wilson, Gladwell \& Cunningham, 1984) it is clear that the positive-feedback mechanism which promotes the LH surge involves a substantial release of LHRH from the median eminence. Indeed, it is not surprising that this is so, in view of the substantially reduced responsiveness of the anterior pituitary gland to LHRH in the laying hen. The significance of the present evidence for a maturational increase in LHRH neuronal activity in the pullet is that it appears to represent a neural correlate of the changing feedback relationship between the ovary and the hypothalamicpituitary complex.

We thank Professor T. R. Morris for provision of poultry-rearing facilities at Lane End Farm, Shinfield, Reading; Dr. S. Lynch for LHRH antiserum; and Professor R. P. Millar for synthetic chicken LHRH. This work was supported by the AFRC (Grant 45/189).

\section{References}

Becker, J. \& Ramirez, V.D. (1980) Dynamics of endogenous catecholamine release from brain fragments of male and female rats. Neuroendocrinology 31. 18-25.

Bonney, R.C., Cunningham, F.J. \& Furr, B.J.A. (1974) Effect of synthetic luteinizing hormone releasing hormone on plasma luteinizing hormone in the female domestic fowl Gallus domesticus. J. Endocr. 63, 539-547.

Drouva, S.V., Epelbaum, J. \& Kordon, C. (1982) Hormonal regulation of and ionic requirements for in vitro release of hypothalamic peptides. In Hormonally Active Brain Peptides, pp. 99-123. Eds K. W. McKerns \& V. Pantic. Plenum Press, New York.

Duncan, D.B. (1955) Multiple range and multiple F tests. Biometrics, 11, 1-42.

Follett, B.K., Scanes, C.G. \& Cunningham, F.J. (1972) A radioimmunoassay for avian luteinizing hormone. $J$. Endocr. 52, 359-378.

Furr, B.J.A. (1969) Identification of steroids in the ovaries and plasma of laying hens and the site of production of progesterone in the ovary. Gen. comp. Endocr. 13, 506.

Gallardo, E. \& Ramirez, V.D. (1977) A method for the superfusion of rat hypothalami : secretion of luteinizing hormone-releasing hormone (LH-RH). Proc. Soc. exp. Biol. Med. 155, 79-84.

Knight, P.G. (1983) Variations in hypothalamic luteinizing hormone releasing hormone content and release in titro and plasma concentrations of luteinizing hormone and testosterone in developing cockerels. $J$. Endocr. 99, 311-319.

Knight, P.G., Gladwell, R.T. \& Cunningham, F.J. (1981)
Effect of gonadectomy on the concentrations of catecholamines in discrete areas of the diencephalon of the domestic fowl. J. Endocr. 89, 389-397.

Knight, P.G., Cunningham, F.J. \& Gladwell, R.T. (1983) Concentrations of immunoreactive luteinizing hormone releasing hormone in discrete brain regions of the cockerel: effects of castration and testosterone replacement therapy. J. Endocr. 96, 471-480.

Knight, P.G., Wilson, S.C., Gladwell, R.T. \& Cunningham, F.J. (1984) Hypothalamic contents of LHRH and catecholamines during the ovulatory cycle of the hen (Gallus domesticus). J. Reprod. Fert. 71, 289-295.

Peterson, A.J. \& Webster, M. (1974) Oestrogen concentrations in the peripheral plasma of maturing pullets. Br. Poult. Sci. 15, 569-572.

Ramirez, V.D., Dluzen, D. \& Lin, D. (1980) Progesterone administration in vivo stimulates release of luteinizing hormone-releasing hormone in vitro. Science, N.Y. 208, $1037-1039$.

Rasmussen, D.D. \& Yen, S.S.C. (1983) Progesterone and $20 x$-hydroxyprogesterone stimulate the in vitro release of $\mathrm{GnRH}$ by the isolated mediobasal hypothalamus. Life Sci. 32, 1523-1530.

Rotsztejn, W.H., Charli, J.L., Pattou, E., Epelbaum, J. \& Kordon, C. (1976) In vitro release of luteinizing hormone-releasing hormone (LHRH) from rat mediobasal hypothalamus: effects of potassium, calcium and dopamine. Endocrinology 99, 1663-1666.

Senior, B.E. (1974) Oestradiol concentration in the peripheral plasma of the domestic hen from seven weeks of age until the time of sexual maturity. $J$. Reprod. Fert. 41, 107-112. 
Sharp, P.J. (1973) A comparison of circulating levels of luteinizing hormone in intact and gonadectomized growing fowl. J. Endocr. 61, viii, Abstr.

Sharp, P.J. (1975) A comparison of variations in plasma luteinizing hormone concentrations in male and female domestic chickens (Gallus domesticus) from hatch to sexual maturity. J. Endocr. 67, 211-223.

Sharp, P.J. (1980) Female reproduction. In Avian Endocrinology, pp. 435-454. Eds A. Epple \& M. H. Stetson. Academic Press, New York.

Sharp, P.J. (1983) Hypothalamic control of gonadotrophin secretion in birds. In Progress in Non-mammalian Brain Research, Vol. III, pp. 123-177. Eds G. Nistico \& L. Bolis. CRC Press, Florida.
Sharp, P.J. \& Fraser, H.M. (1978) Control of reproduction. In The Endocrine Hypothalamus, pp. 271-332. Eds S. L. Jeffcoate \& J. S. M. Hutchinson. Academic Press, London.

Williams, J.B. \& Sharp, P.J. (1977) A comparison of plasma progesterone and luteinizing hormone in growing hens from eight weeks of age to sexual maturity. J. Endocr. 75, 447-448.

Wilson, S.C. \& Sharp, P.J. (1975) Effects of progesterone and synthetic LH-RH on the release of $\mathrm{LH}$ during sexual maturation in the hen (Gallus domesticus). $J$. Endocr. 67, 359-369.

Received 13 August 1984 